\title{
What's Beyond Self Efficacy of Emergency Skills Among Medical Students?
}

\author{
Sylvia Mustika Sari* \\ Department of Medical Education, Faculty of Medicine \\ Universitas Jenderal Achmad Yani \\ Cimahi, Indonesia \\ *sylvia.mustikasari@lecture.unjani.ac.id
}

Andri Anugerah

Department of Medical Emergency, Faculty of Medicine Universitas Jenderal Achmad Yani

Cimahi, Indonesia

\begin{abstract}
Self-efficacy is the main driving force for shaping the character of self-directed learning in medical education that also need in performing clinical skills. The Medical Faculty of Unjani has a local content in medical emergency which is achieved in the undergraduate and the clinical stage. This study aims to explore the difference self-efficacy in undergraduate and clinical students on emergency medical skills and its influencing factors. We used a mixed method with an explanatory design. The quantitative method uses a Bandura's self-efficacy questionnaire with a total of 40 respondents in each group. The qualitative method used FGD with 9 respondents at the undergraduate stage and 12 respondents at the clinical stage. As results, we found a higher self efficacy score in clinical phase students and a significant difference $(p>0,05)$ with undergraduate students. In content analysis of quantitative data, we found the positive influence in the outclass skills learning method, the authority in clinical setting and the observation of peers and instructors' performance. Meanwhile, the negative influence comes from previous experience and judgmental feedback from clinical instructor. These results should be valued as a baseline for quality development in our emergency skills learning. Further research should explore more about the impact of students' self efficacy in actual performance.
\end{abstract}

Keywords—self efficacy, mixed method, emergency skill

\section{INTRODUCTION}

Self-efficacy is an individual's belief in his or her ability to organize and carry out a series of actions in life in order to get something that is expected. An individual who has high selfefficacy can be the basis for building greater self-confidence in demonstrating his abilities $[1,2]$. According to Bandura's social cognitive theory, self-efficacy can influence a person's choice of acting and carrying out actions according to his goals. Individuals tend to concentrate on tasks they feel capable of and believe they can complete [3]

\author{
Daswara Djajasasmita \\ Department of Physiology, Faculty of Medicine \\ Universitas Jenderal Achmad Yani \\ Cimahi, Indonesia
}

\author{
Saviera Edison \\ Department of Medical Education, Faculty of Medicine \\ Universitas Jenderal Achmad Yani \\ Cimahi, Indonesia
}

Self-efficacy is the main driving force for shaping the character of self-directed learners needed in medical education. In practice, self-efficacy is also needed to assess the learning process of a self-directed learner. Self-directed learning (SDL) is a learning process that begins when learners have the initiative to support the learning process so that they can collaborate on the knowledge gained, criticize, reflect on this knowledge, know their abilities, know their goals in learning, choose the desired learning strategies, and can evaluate learning outcomes. Learners who start their learning activities with self-efficacy and develop independent learning strategies will show better progress in achieving goals [4].

Factors that can affect self-efficacy so as to increase selfconfidence are the results of previous experiences, experiences based on observations of others, verbal / social persuasion, and thoughts that are owned by oneself [4-6]. The results of previous experiences are the most influential in self-efficacy [1]. These factors will affect the performance of learners in academics

In accordance with the role of SDL in medical education, self-efficacy plays an important role for students in mastering competencies [7]. Miller in his pyramid explains that in mastering competence, a cognitive foundation is needed in the form of knows and knows how, someone who has good cognitive will also have good self-efficacy $[7,8]$. The two cognitive foundations build self-efficacy which can generate self-confidence as a basis for performing a clinical skill or further competency mastery.

One of the clinical skills that must be achieved in a doctor's competence is medical emergency skills. Medical emergencies is a branch of medicine with the priority of evaluating, diagnosing, managing and preventing unexpected illnesses and injuries. Medical emergencies require special competence in knowledge and skills [9]. Medical emergencies themselves are 
divided into trauma and non-trauma cases. The Faculty of Medicine, Universitas Jenderal Achmad Yani (UNJANI) has a local content of medical emergencies in accordance with its vision, namely to make the Faculty of Medicine superior at the national level in the field of medical emergencies. Based on the vision, it is expected that faculty graduates can excel in the field of medical emergencies compared to graduates from other medical faculties [10].

In achieving its goal as local content, students need good mastery of the material. Mastery of clinical skills material begins with good self-efficacy in students related to mastery of medical emergency material. The medical emergency curriculum at the Faculty of Medicine is studied in two stages of education, namely the undergraduate and professional stages. At the undergraduate stage, trauma and non-trauma cases are studied in medical emergency blocks through tutorial learning methods, group discussions, and medical skills training, which will then be deepened further at the professional stage. At the professional stage, these cases are studied in medical emergency clinic rotation through the bed side teaching learning method, case presentation, morning report, clinical tutorial. With the block and medical emergency clinic rotation, it is hoped that students can achieve the vision of the Faculty [10].

With the two stages of learning, it proves that students in the clinical stage will have better self-efficacy due to more experience. This is as stated by Bandura where experience in learning is the most influential factor in self-efficacy. In addition, there are also other factors that affect self-efficacy, namely internal and social aspects $[1,2,6]$.

Regarding self-efficacy in mastery of medical emergency clinical skills, Avegno conducted research on self-assessment of ability in clinical skills in medical emergencies using selfassessment instruments [11]. Self-assessment is differentiated based on groups of people who have attended skills training and who have not followed skills. The results showed that people who had participated in the training had higher selfconfidence. Based on this description, self-efficacy has an important role in mastering clinical skills [11].

The importance of self efficacy in clinical skills performance and the fact that medical emergencies is a local content of Unjani medical curriculum, then this is what underlies the researchers to find out the differences in selfefficacy of undergraduate and professional stage students on clinical emergency medical skills and factors that influence it.

\section{METHODS}

\section{A. Research Design}

We conducted a mixed method approach (quantitative and qualitative) with an explanatory design $[12,13]$. Quantitative research with a cross sectional design in this study measured variables at the same time. This method is used to determine the differences in the self-efficacy of undergraduate and clinical stage students on emergency medical skills with a questionnaire. For dept findings, we combined the qualitative data from Focus Group Discussion (FGD) to determine the factors that affect self-efficacy. The transcript from qualitative data were categorized and analyzed using thematic content analysis to differentiate the positive and negative influence in self efficacy.

\section{B. Respondents}

The research respondents were undergraduate medical students who had passed the medical emergency block and clinical students who had passed the medical emergency clinic rotation. The number of respondents involved was 80 people who were divided into two groups, where the sample was determined using simple random sampling. In qualitative research, it was divided into two FGD groups. For the undergraduate stage there were 9 respondents while at the clinical stage there were 12 respondents. This is in accordance with the principles of FGD implementation.

\section{Research Instruments}

Prior to the study, the questionnaire used for quantitative research was compiled first and then tested the validity with face validity expert reviews to measure the self-efficacy assessment. Face validity is carried out (1) for medical education lecturers to assess self-efficacy, (2) lecturers in the medical emergency department to review the contents of the medical emergency clinical skills question item. The results of the validity test showed that of the twenty-three questions in the questionnaire there were three invalid statements so that changes were made. The assessment of the reliability test was carried out by statistical tests (Cronbach's aplha) with a result of 0.920 which means the questionnaire is reliable.

The qualitative data were collected through a Focus Group Discussion. FGD is a semi-structured interview using several questions that have been formulated with the aim of obtaining qualitative data [12]. The data retrieved until saturation occurs, namely when the data obtained has no variation.

\section{Ethical Clearence}

This study has been approved by the Ethics Committee of UNJANI and conducted with respect for the respondent's autonomy rights.

\section{RESULTS}

\section{A. The Difference of Self Efficacy}

The undergraduate students have a mean self-efficacy score of 67.67, with a maximum score of 95.22. This score is included in the feel capable category. A self-efficacy score of more than 50 is included in the category of feeling capable of taking action. The data also has a high variation in data when viewed based on the standard deviation. The minimum score obtained was 34.78 . 
For Clinical Students, the mean score of Self Efficacy in medical emergency clinical skills was 74.4. The standard deviation is 8.87 , this shows that the data variation is better than at the undergraduate stage. The data shown in Table 1.

TABLE I. The DIFFERENCE OF SELF EFFICACY IN UNDERGRADUATE AND CLINICAL STUDENTS

\begin{tabular}{|l|c|c|}
\hline \multirow{2}{*}{ Indicator } & \multicolumn{2}{|c|}{ Students } \\
\cline { 2 - 3 } & Undergraduate & Clinical \\
\hline Mean & $67,67(\max 100)$ & $74,40(\max 100)$ \\
\hline Median & $69,34(\max 100)$ & $73,69(\max 100)$ \\
\hline SD & 12,58 & 8,87 \\
\hline Min & $34,78(\max 100)$ & $61,74(\max 100)$ \\
\hline Max & $95,22(\max 100)$ & $96,96(\max 100)$ \\
\hline P value & \multicolumn{2}{|c|}{$0.007 *$} \\
\hline
\end{tabular}

Based on the results of the study, it was found that the mean score of self-efficacy on clinical emergency medical skills at the clinical stage was higher than that of undergraduate students. The results of statistical tests showed that there was a significant difference in self-efficacy towards medical emergency clinical skills among students at the clinical stage and undergraduate students.

\section{B. The Influencing Factors in Self Efficacy}

We conducted the qualitative data analysis to find a dept understanding about factors that affect the students' self efficacy. Using content analysis, we divided the data into two categories such as the positive and negative influence in students' self efficacy.

1) Positive influence: In the undergraduate students, we found the positive influence themes such as: 1) skills laboratory "Outclass" method in emergency block; 2) observation of peers and instructor's performance and 3) get a good mark in OSCE.

"I found I can perform good when I pass the OSCE.." (SK_04)

"The outclass method is quite fun, and we performed somehow in more realistic setting." (SK_08)

"When I saw my friends performance. I know I can be the same" (SK_07)

Besides, the mannequins and video of skills performance from their instructor in emergency block are factors that can increase self-efficacy. During skills learning, the students' experience when observing instructor and peer performance also have a positive influence in their self efficacy.

In clinical phase, the positive influence was found from the themes as follows: 1) the authority in emergency patients' management; 2) the emergency skills as a local content.

"I will be confidence enough if the doctor give me a change" (PR_02)
"I feel that is our character. I want to be the emergency practitioner" (PR_05)

The authority to take action in emergency patients during clinical phase seems to be the most positive influence in students' self efficacy. Moreover, the value of local content of Faculty found to be a positive influence as well.

2) Negative influence: Based on our FGD results, the undergraduate and clinical phase students have a negative influence that can reduce their efficacy during emergency skills' performance. The themes that represent the negative influence such as 1) previous experience and 2) feedback from instructors and clinical expertise.

The students' previous experience such as mistakes in skills performance during skills learning in undergraduate and in the real setting in clinical phase seems to be the high factor that influence their self efficacy negatively.

"When the airway skills performance, the ETT seems to entered the esophagus, so in the next performance I feel that I just not going to make it right." (PR_09)

Moreover, the feedback about students' performance during skills learning both in undergraduate and clinical skills found to be a negative influence. This impact can produce by a judgmental feedback from lecture according students' performance.

"He said I am not good at; I am not going to be a good doctor. That's means a lot for me." (PR_07)

We found that the form of negative feedback from clinical instructors is the main point of decreasing students' efficacy.

\section{DISCUSSION}

Self efficacy is an important part of conceptualization in emergency skills performance. Based on our results, we found that our students' self efficacy was better during clinical phase with a significant difference. These findings represent that clinical exposure and real setting in Emergency Department has give a positive influence for students to perform their skills. Clinical students have more experience than undergraduate because clinical students have faced more actual cases of medical emergencies. In accordance with the research conducted by Avegno, regarding the higher self-efficacy in students who have attended skills training before [11].

In our context, the undergraduate students get a learning experience about clinical emergency medical skills in medical emergency blocks. In this block, students should achieve the learning outcome in emergency skills competence with the knowledge and psychomotor based learning such as tutorials and skills laboratory activities. Our innovation in emergency skills learning is the outclass skills learning. The "outclass" means literally we set the parking lot to be a simulation setting of prehospital and hospital with simulation cases as well. The group of students should arrange their patients' management during prehospital and hospital setting and observed by 
instructors. In the end, they will get a feedback from expert in medical emergency. Based on our results, this "outclass" method have a positive impact in undergraduate students' self efficacy.

Based on the experiences gained in the learning process, students have formed self-efficacy in carrying out medical emergencies. Self efficacy can be influenced by several factors including previous experience, observation of others, verbal / social persuasion, and also self-concept [14]. Meanwhile, Skinner said that someone who is given a continuous stimulus in the sense of a strengthened stimulus will produces a better response $[6,14,15]$.

Clinical students are already in the clinical environment and have also involved patients. According to Bandura, self efficacy can be influenced by several factors including previous experience, observation of others, verbal / social persuasion, and self-concept [16-18]. Clinical students have better self-efficacy than the undergraduate stage. Clinical students have more experience so that in terms of application they have better self-efficacy. This is in accordance with one of the factors that influence self-efficacy, namely experience [4]. Clinical students have also been in clinical situations, this is in accordance with social cognitive theory, namely humans have the ability to think and the ability to observe the environment $[3,6]$.

In line with the theory of experiential learning, students will learn when faced with previous problems or new problems that are likely to be used as conceptualization and self-reflection in the students' minds as a tool to carry out new experiences that they will face. In the experiential learning theory, there is a discussion that leads to the socio-cultural theory which says that exposure from the environment has a more dominant role compared to individual experiences. When clinical students enter the clinical setting (hospital, etc.), they will learn through a different learning environment than at the undergraduate. Students will observe the processes that occur in the clinical environment, paying attention to when emergency room doctors practice emergency measures for emergency patients so that later students can conceptualize this knowledge into themselves and they have the provisions to carry out these actions when needed. In our qualitative analysis, despite the positive we also found the negative influence of self efficacy namely the judgmental feedback and also the previous experience especially in underperforming skills or mistakes in performance. This finding also relates with the experiential learning theory as a negative experience that will have impact on students' self efficacy.

\section{CONCLUSION}

Our findings conclude that experience in real clinical setting, the "outclass" skills learning method and skills assessment was the important factor to increase self efficacy in emergency skills performance among medical students. Besides, we have to consider the negative influence such as judgmental feedback in underperformance students. This results can be a baseline in our quality development especially in emergency skills learning.

\section{REFERENCES}

[1] J. Feist and G.J. Feist, Theories of Personality 7th Edition. United States: McGrawHill, 2008.

[2] D.P. Schultz and S.E. Schultz, Theories of Personality. Boston: Cengage Learning, 2016.

[3] F. Pajares, Overview of Social Cognitive Theory and of Self-Efficacy. 1997. [Online] Retrieved from: http://people.wku.edu/richard.miller/banduratheory.pdf

[4] M.Z. Hassan, M.T. Hossain, and M.A. Islam, "Factors Affecting SelfEfficacy Towards Academic Performance: A Study on Polytechnic Students in Malaysia," Adv Environ Biol., vol. 8, pp. 695-705, 2014.

[5] C.S. Hall and G. Lindzey, Theories of Personality. NY: Wiley, 1957.

[6] T. Doran, K. Mann, A. Scherpbier, and J. Spencer, Medical Education: Theory and Practice. United Kingdom: Elseviers Churchill Livingstone, 2011.

[7] T. Dornan, M. Karen, A. Scherpbier, and J. Spencer, Medical Education Theory and Practice. UK: Churchill Livingstone Elsevier, 2011.

[8] G.E. Miller, "The assessment of clinical skills/competence/performance," Academic medicine, vol. 65, pp. 63-67.

[9] A.M. Kelly, "A problem-based learning resource in emergency medicine for medical students," J Accid Emerg Med. Vol. 17, pp. 320-323, 2000.

[10] UNJANI, Buku Pedoman Akademik Dan Kemahasiswaan Program Studi Pendidikan Dokter. Cimahi: UNJANI, 2015.

[11] J.L. Avegno, H. Murphy-Lavoie, D.P. Lofaso, and L. Moreno-Walton, "Medical students' perceptions of an emergency medicine clerkship: an analysis of self-assessment surveys," International journal of emergency medicine, vol. 5, pp. 25, 2012

[12] J.W. Creswell and J.D. Creswell, Research design: Qualitative, quantitative, and mixed methods approaches. Sage publications, 2017.

[13] M. Tavakol and J. Sandars, Quantitative and Qualitative Methods in Medical Education Research. (Gibbs T, ed.). United Kingdom: An International association for medical education, 2014.

[14] R. Wagler, “The Impact of Vicarious Experiences and Field Experience Classroom Characteristics on Preservice Elementary Science Teaching Efficacy,” Electron J Sci Educ., vol. 15, pp. 1-28, 2011.

[15] B.F. Skinner, "The generic nature of the concepts of stimulus and response," The Journal of General Psychology, vol. 12, pp. 40-65, 1935.

[16] M. Weegar and D. Pacis, A Comparison of Two Theories of Learning -Behaviorism and Constructivism as applied to Face-to-Face and Online Learning. E-Leader Manila, 2012, pp. 1-20.

[17] A. Bandura, "Guide for constructing self-efficacy scales. Self-efficacy beliefs Adolesc," Self-efficacy beliefs of adolescents, vol. 5, pp. 307337, 2006.

[18] A. Bandura, Social cognitive theory of personality. Handbook of personality, vol. 2, pp. 154-196, 1999. 